\title{
Household Coverage with Adequately lodized Salt and lodine Status of Nonpregnant and Pregnant Women in Uzbekistan
}

\author{
Fabian Rohner, ${ }^{1}$ Fakhriddin Nizamov, ${ }^{2}$ Nicolai Petry, ${ }^{1}$ Feruza Yuldasheva, ${ }^{3}$ Saydiganikhodja Ismailov, ${ }^{4}$ \\ Rita Wegmüller, ${ }^{1}$ Sufang Guo, ${ }^{2}$ James P. Wirth, and Bradley A. Woodruff ${ }^{1}$
}

Background: Globally, iodine deficiency has been drastically reduced since the introduction of salt iodization programs; nonetheless, many populations remain at-risk for iodine deficiency. This study aimed to assess the iodine status among women of reproductive age in Uzbekistan and to identify factors associated with iodine deficiency, including the availability of adequately iodized salt at the household level.

Methods: A cross-sectional household survey was conducted to produce region-specific estimates of the household coverage with adequately iodized salt and iodine status among women for each of the 14 regions in Uzbekistan. Other information, such as socioeconomic status, lactation and pregnancy, residence, age, and consumption of iodine supplements, was also collected.

Results: Overall, $36 \%$ of 3413 households had adequately iodized salt (iodine concentration $>15$ ppm [parts per million (mg I/kg salt)]), 20\% had inadequately iodized salt (5-14 ppm), and 44\% had salt without detectable iodine $(<5 \mathrm{ppm})$. Adequate iodization was found in $33.2 \%$ of the 2626 salt samples taken from retail packages labeled as "iodized," $36.5 \%$ of the 96 samples taken from retail packages without mention of iodization, and $50.5 \%$ of the 674 samples without the original packaging $(p<0.001)$. The median urinary iodine concentration (UIC) of $140.9 \mu \mathrm{g} / \mathrm{L}$ (95\% confidence interval [CI 132.4-150.7]) in nonpregnant nonlactating women indicated adequate iodine status, while for nonpregnant lactating and pregnant women, the median UIC of $112.9 \mu \mathrm{g} / \mathrm{L}$ [CI 99.3-128.4] and 117.3 $\mu \mathrm{g} / \mathrm{L}$ [CI 101.8-139.9], respectively, indicated borderline adequacy. Significant differences in UIC $(p<0.001)$ were found between nonpregnant nonlactating women living in households with adequately iodized salt (UIC $208.9 \mu \mathrm{g} / \mathrm{L}$ ), inadequately iodized salt (UIC $139.1 \mu \mathrm{g} / \mathrm{L}$ ), and noniodized salt (UIC $89.9 \mu \mathrm{g} / \mathrm{L}$ ). Conclusions: Coverage with adequately iodized salt is low in Uzbekistan, and women in households with poorly iodized salt have substantially worse iodine status; claims on packaging about salt iodization do not reflect salt iodine content. This highlights the importance and effectiveness of salt iodization and the need to strengthen this program in Uzbekistan.

Keywords: iodine status, iodine deficiency, salt iodization, salt iodine levels, pregnant women, women of reproductive age, Uzbekistan

\section{Introduction}

$\mathbf{S}^{1}$ NCE THE 1980s, THE number of national salt iodization programs has increased. Subsequently, the amount of dietary iodine consumed by the global population has also increased. Despite these improvements, over 1.8 billion people are estimated to remain at risk for iodine deficiency $(1,2)$. Severe iodine deficiency has profound effects on the growth and development of the fetus and the young child $(3,4)$ as well as on the cognitive performance of school-age children. Even mild to moderate iodine deficiency has impacts on the developing body (5).

\footnotetext{
${ }^{1}$ GroundWork, Fläsch, Switzerland.

${ }^{2}$ UNICEF Uzbekistan, Tashkent, Uzbekistan.

${ }^{3}$ Scientific Epidemiological Laboratory for the Determination of Iodine in Urine and Salt, Republic Specialized Scientific Practical Medical Centre of Endocrinology, Tashkent, Uzbekistan.

${ }^{4}$ Endocrinology Department, Tashkent Pediatric Medical Institute, Tashkent, Uzbekistan.

(C) Fabian Rohner et al., 2020; Published by Mary Ann Liebert, Inc. This Open Access article is distributed under the terms of the Creative Commons Attribution Noncommercial License (http://creativecommons.org/licenses/by-nc/4.0/) which permits any noncommercial use, distribution, and reproduction in any medium, provided the original author(s) and the source are cited.
} 
Data on household coverage with iodized salt are regularly collected through the Demographic Health Surveys (DHS) and the Multiple-Indicator Cluster Surveys (MICS). With few exceptions, these data reveal substantial increases in iodized salt coverage worldwide (2). Nonetheless, most DHS and MICS use rapid test kits, which are qualitative tests that only distinguish whether salt contains any iodine or no iodine (6). As such, these tests do not allow conclusions on the adequacy of salt iodization levels or the coverage with adequately iodized salt.

The most recent MICS in Uzbekistan conducted in 2006 reported that 53\% of households consumed iodized salt (7) as measured using rapid test kits. In addition, there have been several school-based surveys in Uzbekistan since 1998 that measured salt iodine content from salt samples children brought from home and measured urinary iodine concentration (UIC) in school-age children (8). Although the authors of the report on school-based iodine surveys did not provide median UIC, they posited a steadily increasing proportion of children with UIC $>100 \mu \mathrm{g} / \mathrm{L}$ (a threshold used to determine "iodine adequacy"): 0\% (1998), 46\% (2004), 64\% (2010), and $76 \%$ (2016). The authors also reported that the proportion of adequately iodized salt samples steadily increased in the same time periods: $8 \%$ (1998), 45\% (2004), 62\% (2010), and $75 \%$ (2016). For the school-based surveys, salt iodine content was determined using iodometric titration, but salt samples were brought by the children to the schools for collection.

Uzbekistan introduced a law in 2007, which mandated a salt iodization level of $40 \pm 15 \mathrm{mg}$ iodine $/ \mathrm{kg}$ salt beginning in 2011 .

Recently, the utility of estimating a population's iodine status by sampling school-age children has been debated, since school-age children are not the primary target group of iodine interventions (9). The primary beneficiaries are unborn and very young children, and thus, surveys should measure UIC in pregnant women and nonpregnant women of reproductive age (both nonlactating and lactating), as they may become pregnant (10). To fill this important data gap in Uzbekistan, the Uzbekistan Nutrition Survey (UNS) quantitatively measured household salt iodine content and UIC in nonpregnant and pregnant women.

\section{Materials and Methods}

\section{Survey design and participants}

The UNS was a household-based survey conducted in October and November 2017. Two-stage sampling was carried out with makhallas, the smallest administrative units, as the primary sampling unit, and households as the secondary sampling unit. All pregnant women from selected households were included, but nonpregnant women aged 15-49 years were only recruited in every second selected household. Due to the absence of a recent national population census, updated population estimates for each of the more than 4000 makhallas in Uzbekistan were requested from local health authorities. These updated estimates were then entered into a centralized database. Each of the 14 administrative regions served as a stratum.

Within each of the 14 strata, 25 clusters (makhalla or segment thereof, in larger makhallas) were selected with a probability proportional to the population size. To ensure the most accurate sampling frame for the selection of households, dedicated teams conducted door-to-door visits to update household lists for each selected primary sampling unit a few weeks before survey data collection. In each selected primary sampling unit, 12 households were selected at random with equal probability, resulting in a target sample size of 4200 households.

The UNS was designed to produce results with acceptable precision for nonpregnant nonlactating women in each of Uzbekistan's 14 regions, but only national estimates for nonpregnant lactating women and pregnant women because they are relatively rare when recruited from households.

\section{Data collection and laboratory analysis}

The household head or another knowledgeable adult was administered the household questionnaire, which included questions to estimate socioeconomic status and household salt intake. At each household, a small salt sample (30-50 g) was requested, which was collected and stored in airtight containers for later quantitative analysis. Subsequently, an individual questionnaire for each eligible woman participant was completed. This questionnaire included, among other modules, current breastfeeding, current lactation, and in the case of pregnant women, gestational age of the current pregnancy. Finally, participants were requested to provide a urine sample, which was aliquoted and stored at $2-8^{\circ} \mathrm{C}$ regionally for up to a week until transportation to Tashkent.

Salt iodine content was measured quantitatively using iodometric titration according to standard guidelines (11) by the Scientific Epidemiological Laboratory of the Center for the Scientific and Clinical Study of Endocrinology in Tashkent. In addition to the laboratory's established internal quality control scheme, a high-quality salt sample (Südwestdeutsche Salzwerke AG, Heilbronn, Germany) was used as external quality control and run roughly every 30 th sample.

UIC was determined using the Sandell-Kolthoff reaction method (12) by the same laboratory, which in the past has successfully participated in the laboratory validation rounds for the Ensuring the Quality of Urinary Iodine Procedures (EQUIP) program organized by the U.S. Centers for Disease Control and Prevention, Atlanta, Georgia. In addition, external quality control samples with known iodine concentrations were run every 30th sample. These external samples were provided by the Laboratory of Human Nutrition, Institute of Food, Nutrition and Health, ETH Zurich, Switzerland. Of note, the iodine concentrations of these quality control salt and urine samples were unknown to the performing laboratory, and the laboratory continued analysis only if the results were within a preset range, as indicated by the research team.

\section{Case definitions}

Salt iodine concentrations were categorized as follows: $<5 \mathrm{ppm}$, noniodized; 5-14.9 ppm, inadequately iodized; $\geq 15 \mathrm{ppm}$, adequately iodized. These categories are reflecting international recommendations (11) and methodological limitations (13).

Iodine concentrations from spot urine specimens cannot be used for individual status assessment because UIC shows large diurnal and day-to-day variability (14). The population of nonpregnant nonlactating women was classified using the following median UIC (11): $<20 \mu \mathrm{g} / \mathrm{L}$ (population severely deficient), $20-49 \mu \mathrm{g} / \mathrm{L}$ (population moderately deficient), 50-99 $\mu \mathrm{g} / \mathrm{L}$ (population mildly deficient), 100$199 \mu \mathrm{g} / \mathrm{L}$ (population adequate), 200-299 $\mu \mathrm{g} / \mathrm{L}$ (population 
above requirements), $\geq 300 \mu \mathrm{g} / \mathrm{L}$ (population excessive). For nonpregnant lactating women, only two categories were defined: $<100 \mu \mathrm{g} / \mathrm{L}$ (population inadequate) and $\geq 100 \mu \mathrm{g} / \mathrm{L}$ (population adequate). For pregnant women, the classifications were as follows: $<150 \mu \mathrm{g} / \mathrm{L}$ (population inadequate), $150-249 \mu \mathrm{g} / \mathrm{L}$ (population adequate), and $\geq 250 \mu \mathrm{g} / \mathrm{L}$ (population more than adequate or excessive).

\section{Data management and statistical analysis}

For data collection at the household level, tablet computers were used for direct data entry using Open Data Kit software. Laboratory data were double-entered using Microsoft Excel, version 2010. Data analysis was done using SPSS version 22 with the complex survey module. Standardized statistical weights calculated separately for each target group accounted for the unequal selection probability in the 14 strata.

Normality of distribution of continuous data was checked using histograms and calculating skewness and kurtosis. For normally distributed data, the statistical precision of estimates of means was assessed using $95 \%$ confidence limits, which were calculated accounting for the complex sampling. For non-normally distributed UICs, 95\% confidence limits around median values were calculated using bootstrapping. Because bootstrapping cannot account for the complex sampling, precision is overestimated, and the confidence limits calculated are artificially narrow. Therefore, to assess the statistical difference in UIC by subgroup, geometric mean UIC for subgroups was calculated. This procedure yielded geometric means that were highly comparable with the median UIC values for each subgroup. In addition, this approach has the advantage that the 95\% confidence intervals are calculated accounting for the complex sampling design, and a generalized linear model can be applied to obtain $p$-values appropriate for cluster sampling and stratification.

Household socioeconomic status was assessed using data on household characteristics and assets and applying the principal component analysis to calculate an index of household wealth, which was subsequently used to classify households into wealth quintiles $(15,16)$.

Interpolation mapping techniques were used to present the geographic variation of adequately iodized salt and geometric mean UIC. Specifically, we linked cluster-specific estimates of the proportion of households with adequately iodized salt and the geometric mean UIC in nonpregnant nonlactating with GPS coordinates for each cluster. To estimate the distributions of each variable for all of Uzbekistan, interpolation using inverse distance weighting was applied (17). For this procedure, the distance coefficient $\mathrm{P}$ was set to 2.0, limiting the rate of influence of the cluster-specific estimate as the distance from the point increases. This distance coefficient $\mathrm{P}$ was chosen due to the relatively small distance between many of the clusters selected for this survey. As the final step, bilinear resampling was applied to smooth the pixel values contained in the interpolated raster file (18). Geographic analysis was conducted using Quantum GIS 3.4 (19). Because the population density is very low in large areas of Navoi and Karakalpakstan, there are many areas of these regions that had few or no clusters. During the interpolation mapping process, this led to a biased visualization in these regions, as the interpolation was based on a very small number of clusters. To correct for this bias, districts with a population density $<5$ people $/ \mathrm{km}^{2}$ (20) on average were masked to indicate that these areas should be interpreted with caution (i.e., Tomdi, Uchquduk, Aral Sea, Mo'ynoq, and Qo'ng'irot). The mask is semitransparent so that the proportion of households with adequately iodized salt in clusters in these districts can be displayed.

\section{Ethics and consent}

Ethical approval for the survey was obtained from the Ministry of Health of Republic of Uzbekistan Ethics Committee (Letter 2/12, dated March 17, 2017), as well as from the Health Media Laboratory IRB, an additional external IRB appointed by UNICEF (approved on February 27, 2017; no. 015RUZB 1). Informed verbal consent was sought from the

TABle 1. Proportion of Households with Adequately Iodized Salt, by Various Characteristics, UzbeKistan 2017

\begin{tabular}{|c|c|c|c|c|}
\hline Characteristic & $\mathrm{n}^{\mathrm{a}}$ & $\%^{\mathrm{b}}$ & {$[C I]^{\mathrm{c}}$} & $\mathrm{p}-$ Value $e^{\mathrm{d}}$ \\
\hline \multicolumn{5}{|l|}{ Residence } \\
\hline Urban & 481 & 47.8 & [42.6-53.0] & \multirow[t]{2}{*}{$<0.001$} \\
\hline Rural & 763 & 31.4 & [28.6-34.3] & \\
\hline \multicolumn{5}{|l|}{ Region } \\
\hline Andijon & 37 & 15.5 & [10.8-21.8] & \multirow[t]{14}{*}{$<0.001$} \\
\hline Bukhara & 102 & 41.8 & {$[31.0-53.4]$} & \\
\hline Ferghana & 98 & 38.0 & {$[30.5-46.1]$} & \\
\hline Jizzakh & 80 & 32.9 & {$[23.1-44.5]$} & \\
\hline Karakalpakstan & 51 & 19.5 & {$[12.0-30.0]$} & \\
\hline Kashqadarya & 42 & 24.3 & {$[15.8-35.4]$} & \\
\hline Khorazm & 239 & 88.2 & {$[83.0-92.0]$} & \\
\hline Namangan & 37 & 13.8 & [9.5-19.6] & \\
\hline Navoiy & 130 & 55.6 & [45.3-65.4] & \\
\hline Samarkand & 37 & 15.1 & [10.2-21.7] & \\
\hline Surkhandarya & 38 & 16.0 & {$[11.3-22.1]$} & \\
\hline Sirdarya & 68 & 27.8 & [19.9-37.3] & \\
\hline Tashkent City & 173 & 73.0 & [63.7-80.6] & \\
\hline Tashkent Oblast & 112 & 43.6 & {$[35.8-51.7]$} & \\
\hline \multicolumn{5}{|l|}{ Wealth quintile } \\
\hline Lowest & 133 & 20.7 & {$[17.5-24.4]$} & \multirow[t]{5}{*}{$<0.001$} \\
\hline Second & 203 & 29.8 & [25.9-34.1] & \\
\hline Middle & 269 & 39.3 & {$[35.2-43.5]$} & \\
\hline Fourth & 315 & 45.7 & {$[41.6-50.0]$} & \\
\hline Highest & 317 & 45.5 & [40.4-50.7] & \\
\hline \multicolumn{5}{|l|}{ Packaging of salt } \\
\hline $\begin{array}{l}\text { Original packaging } \\
\text { stating salt } \\
\text { is iodized }\end{array}$ & 905 & 33.2 & [30.8-35.7] & \multirow[t]{3}{*}{$<0.001$} \\
\hline $\begin{array}{l}\text { Original packaging } \\
\text { without mention } \\
\text { of iodization }\end{array}$ & 35 & 36.5 & [24.9-49.8] & \\
\hline $\begin{array}{l}\text { Undetermined, not } \\
\text { in original package }\end{array}$ & 300 & 50.1 & [45.1-55.0] & \\
\hline
\end{tabular}

${ }^{\text {a }}$ The $n$ 's are unweighted numerators in each subgroup; the sum of subgroups may not equal the total because of missing data.

${ }^{b}$ All percentages except region-specific estimates are weighted for unequal probability of selection.

${ }^{c} \mathrm{CI}$ calculated taking into account the complex sampling design.

${ }^{\mathrm{d}}$ Chi-square $p$-value $<0.05$ indicates that the proportion in at least one subgroup is statistically significantly different from the values in the other subgroups.

CI, $95 \%$ confidence interval. 
head of the household or, if absent, from the spouse or other adult household member. For individual questionnaires and urine collection, written informed consent was sought from participating women. Confidentiality of information from the respondents was upheld with utmost care throughout data collection, processing, and analysis.

\section{Results}

\section{Response rates and demographic characteristics}

Overall, 4097 households were randomly selected, of which $3882(94.8 \%)$ consented to participate in the survey and completed the household interview. Only 35 households refused to participate; most nonparticipation was due to extended absence of all household members or absence of a qualified respondent.

Of the 2269 nonpregnant women participating in the UNS, $1848(81.3 \%)$ were nonlactating and $421(18.7 \%)$ were lactating at the time of the survey. For $91.9 \%$ of nonpregnant women, urinary iodine results were obtained. In total, 251 pregnant women were interviewed, $90.4 \%$ of whom had urinary iodine results.

Of the households selected, $77.1 \%$ had a male household head, $69.0 \%$ were located in rural areas, and the mean household size was 5.2 members.

\section{Household coverage with iodized salt}

Among the consenting households, 3791 (97.7\%) reported having salt at home at the time of survey data collection. However, salt iodine results were available from only 3413 households. In the majority of cases, the reason for missing salt iodine content results was insufficient sample quantity, and in a few instances, a lost label.
Of these households, $96.2 \%$ reported during the household interview that their salt was iodized. Of salt samples collected, $79.2 \%$ were in the original packaging stating that salt was iodized, $2.7 \%$ were in the original package but no indication of added iodine could be observed, and $18.1 \%$ of salt samples were not in the original package.

Overall, 43.9\% (95\% confidence interval [CI 41.6-46.3]) of salt samples were not iodized, 19.7\% [CI 18.2-21.4] were insufficiently iodized, and $36.4 \%$ [CI 34.1-38.7] of salt samples were adequately iodized.

Table 1 shows that urban and wealthier households had a higher proportion of adequately iodized salt than rural or poorer households. Salt samples from packages with labels stating that the salt was iodized were less likely to be adequately iodized than from those with labels not claiming to be iodized or those that were not in the original package.

Furthermore, there were substantial regional differences; this is also reflected in Figure 1 showing an interpolated map of the household coverage with adequately iodized salt. Coverage in Khorezm is more homogeneous than in most other regions. The coverage of adequately iodized salt is low in eastern Uzbekistan except for Tashkent City and, to a lesser extent, Tashkent Oblast.

\section{lodine status among nonlactating nonpregnant women of reproductive age}

More than 9 of 10 women had heard about iodized salt and, of these, virtually all were able to cite one or more correct benefits of iodine (mostly "prevents iodine deficiency" and "improves health status").

The median UIC in nonpregnant nonlactating women was $140.9 \mu \mathrm{g} / \mathrm{L}$, indicating iodine overall sufficiency in this subpopulation (Table 2). However, there were considerable

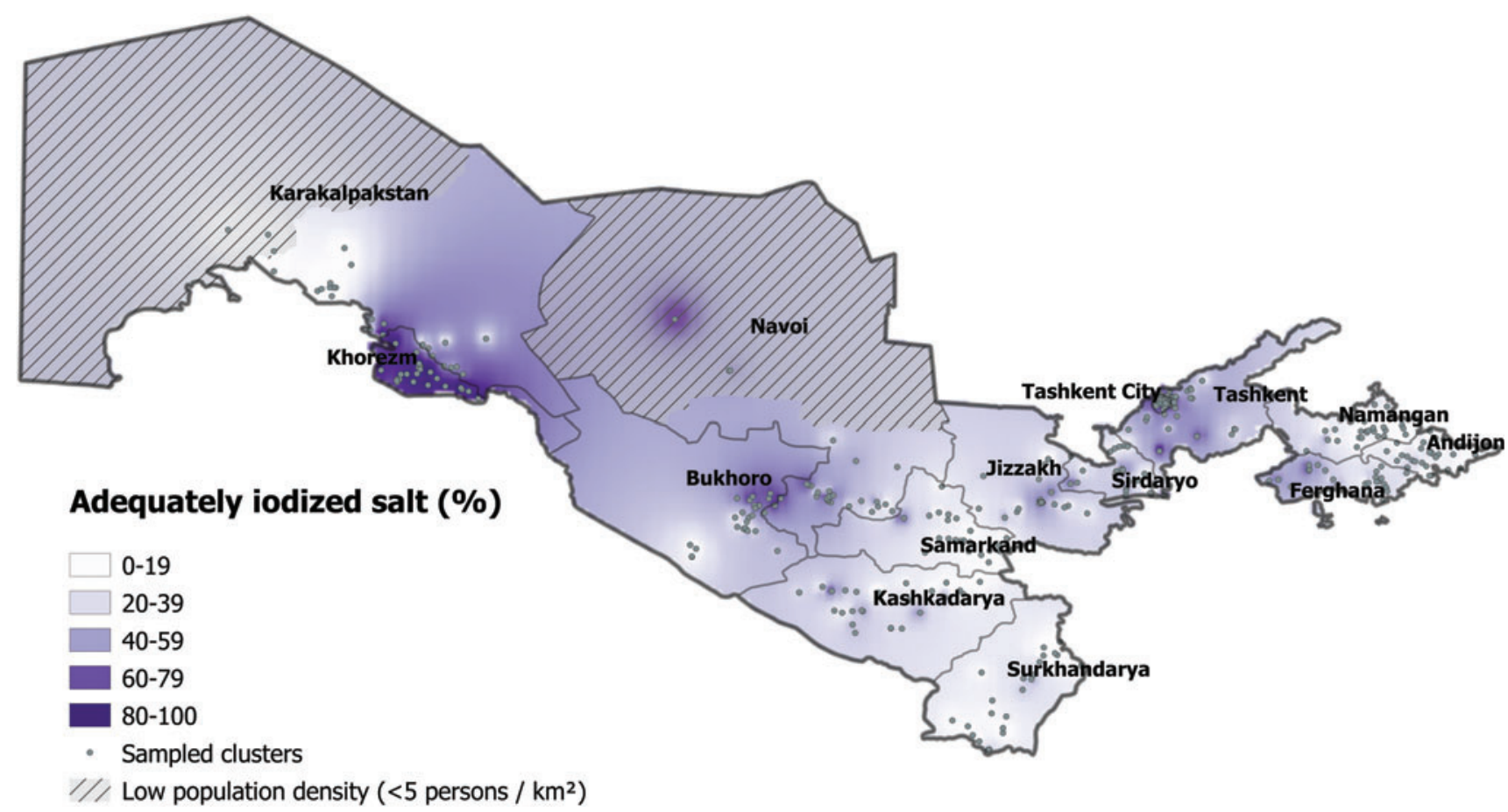

FIG. 1. Geographic distribution of household coverage with adequately iodized salt ( $\geq 15 \mathrm{mg} / \mathrm{kg})$, Uzbekistan 2017 . Color images are available online. 
Table 2. Median Urinary Iodine Concentration in Nonpregnant Nonlactating Women 15-49 Years of Age, UzbeKistan 2017

\begin{tabular}{|c|c|c|c|c|}
\hline Characteristic & $\mathrm{n}$ & Median UIC ${ }^{\mathrm{a}}$ & {$[C I]^{\mathrm{b}}$} & $\mathrm{p}-$ Value $^{\mathrm{c}}$ \\
\hline Total & 1697 & 140.9 & [132.4-150.7] & - \\
\hline \multicolumn{5}{|l|}{ Urban/rural } \\
\hline Urban & 485 & 152.5 & [139.1-163.8] & \multirow[t]{2}{*}{$<0.05$} \\
\hline Rural & 1210 & 136.3 & {$[127.4-149.1]$} & \\
\hline \multicolumn{5}{|l|}{ Region } \\
\hline Andijon & 97 & 120.5 & [87.7-131] & \multirow[t]{14}{*}{$<0.001$} \\
\hline Bukhara & 123 & 238.0 & [205.6-308.6] & \\
\hline Ferghana & 112 & 119.3 & [107.3-139.7] & \\
\hline Jizzakh & 143 & 138.4 & [112.6-196.4] & \\
\hline Karakalpakstan & 128 & 151.0 & [119.5-176.2] & \\
\hline Kashqadarya & 133 & 161.1 & [132.1-183.8] & \\
\hline Khorazm & 155 & 302.3 & [261.5-335.6] & \\
\hline Namangan & 119 & 60.9 & {$[48.1-72.1]$} & \\
\hline Navoiy & 100 & 176.1 & [140.8-194.3] & \\
\hline Samarkand & 114 & 75.9 & {$[67.8-89.1]$} & \\
\hline Surkhandarya & 115 & 131.1 & [115.4-163.3] & \\
\hline Sirdarya & 127 & 111.2 & [97-137.1] & \\
\hline Tashkent City & 119 & 185.0 & [159-209.7] & \\
\hline Tashkent Oblast & 112 & 160.7 & [130.6-195.4] & \\
\hline \multicolumn{5}{|l|}{ Age (in years) } \\
\hline $15-19$ & 270 & 157.0 & [136.8-175.2] & \multirow[t]{7}{*}{0.56} \\
\hline $20-24$ & 242 & 148.2 & {$[122.9-166]$} & \\
\hline $25-29$ & 229 & 149.3 & [122-163.8] & \\
\hline $30-34$ & 259 & 134.7 & [124.2-151.1] & \\
\hline $35-39$ & 207 & 137.0 & [109.8-165.7] & \\
\hline $40-44$ & 219 & 127.2 & [109.4-168.9] & \\
\hline $45-49$ & 268 & 145.8 & [124.2-168.7] & \\
\hline \multicolumn{5}{|l|}{ Wealth quintile } \\
\hline Poorest & 345 & 106.3 & [96.3-124.6] & \multirow[t]{5}{*}{$<0.001$} \\
\hline Second & 324 & 132.8 & [120.2-154.6] & \\
\hline Middle & 360 & 162.4 & [146.4-180.9] & \\
\hline Fourth & 308 & 151.4 & [130-174.9] & \\
\hline Wealthiest & 348 & 163.2 & [152.9-183.0] & \\
\hline \multicolumn{5}{|l|}{ Educational level } \\
\hline Secondary or less & 768 & 138.0 & [124.9-151.9] & \multirow[t]{2}{*}{0.48} \\
\hline Special secondary or more & 929 & 144.8 & [133.2-155.8] & \\
\hline \multicolumn{5}{|c|}{ Level of iodization of household salt } \\
\hline None $(<5 \mathrm{ppm})$ & 669 & 93.1 & [85.9-100.6] & \multirow[t]{3}{*}{$<0.001$} \\
\hline Insufficient $(5-14.9 \mathrm{ppm})$ & 297 & 152.7 & {$[139.1-170]$} & \\
\hline Adequate $(15+\mathrm{ppm})$ & 580 & 214.3 & [196.9-237.2] & \\
\hline
\end{tabular}

The $n$ 's are unweighted denominators in each subgroup; the sum of subgroups may not equal the total because of missing data.

${ }^{\mathrm{a}}$ Medians are weighted for unequal selection probability.

${ }^{\mathrm{b}} \mathrm{CI}$ calculated by bootstrapping without taking into account the complex sampling design.

${ }^{c} p$-Values are calculated using nonparametric median test.

UIC, urinary iodine concentration.

regional differences, with median UIC ranging from 61 to $302 \mu \mathrm{g} / \mathrm{L}$ in the different regions. Also, women from rural and poorer households had lower median UIC. Nonpregnant nonlactating women from households with noniodized salt had the lowest median UIC, followed by those with inadequately iodized salt and finally those with adequately iodized salt, thus demonstrating a strong dose/response relationship between consumption of adequately iodized salt and UIC.

Figure 2 shows the geographic differences in median UIC in nonpregnant nonlactating women. This interpolated map shows that in addition to inter-regional differences, there are substantial within-region variations, in particular in eastern Uzbekistan.

\section{lodine status among lactating nonpregnant women of reproductive age}

Among the 390 nonpregnant lactating women, the median UIC was lower than that for nonpregnant nonlactating women (Table 3). There are differences in this population group by age and wealth quintile, but no consistent trend can be observed. Differences for urban versus rural residence are not statistically significant; however, no regional disaggregation was undertaken due to the small number of nonpregnant lactating women. As was found for nonpregnant nonlactating, there is a strong dose/response relationship between median UIC and household salt iodization adequacy. To 


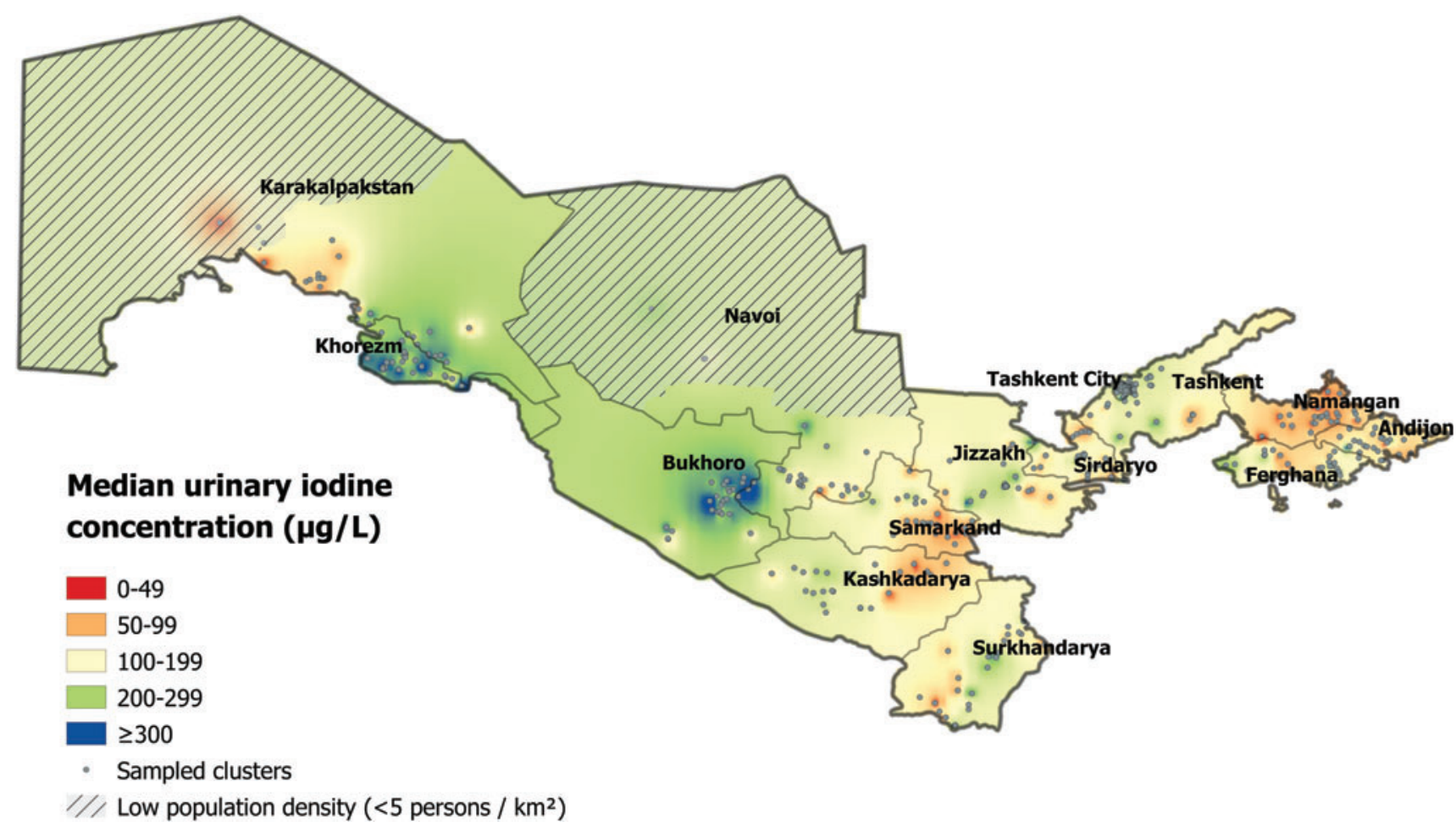

FIG. 2. Geographic distribution of median UIC among nonpregnant nonlactating women 15-49 years of age, Uzbekistan 2017. UIC, urinary iodine concentration. Color images are available online.

Table 3. Median Urinary Iodine Concentration in Nonpregnant Lactating Women 15-49 Years of Age, Uzbekistan 2017

\begin{tabular}{|c|c|c|c|c|}
\hline Characteristic & $\mathrm{n}$ & Median UIC ${ }^{\mathrm{a}}$ & {$[C I]^{\mathrm{b}}$} & $\mathrm{p}-$ Value $^{\mathrm{c}}$ \\
\hline Total & 390 & 112.9 & [99.3-128.4] & - \\
\hline \multicolumn{5}{|l|}{ Urban/rural } \\
\hline Urban & 101 & 122.5 & [88.3-141.9] & \multirow[t]{2}{*}{0.49} \\
\hline Rural & 289 & 109.2 & [93.9-124.3] & \\
\hline \multicolumn{5}{|l|}{ Age (in years) } \\
\hline $15-24$ & 117 & 104.1 & [83-120.2] & \multirow[t]{4}{*}{0.08} \\
\hline $25-29$ & 163 & 105.8 & [91.2-126.7] & \\
\hline $30-34$ & 80 & 185.4 & [134.3-224.8] & \\
\hline $35+$ & 30 & 92.1 & {$[47.8-135.8]$} & \\
\hline \multicolumn{5}{|l|}{ Wealth quintile } \\
\hline Poorest & 86 & 85.5 & [72.1-105.0] & \multirow[t]{5}{*}{$<0.001$} \\
\hline Second & 82 & 107.9 & [73.7-133.3] & \\
\hline Middle & 70 & 135.7 & [105.3-177.9] & \\
\hline Fourth & 75 & 104.1 & [83.9-142.8] & \\
\hline Wealthiest & 74 & 161.5 & [135.4-191.3] & \\
\hline \multicolumn{5}{|l|}{ Educational level } \\
\hline Secondary or less & 143 & 116.0 & [95.1-135.7] & \multirow[t]{2}{*}{0.40} \\
\hline Special secondary or more & 247 & 112.9 & [95.6-132.2] & \\
\hline \multicolumn{5}{|c|}{ Level of iodization of household salt } \\
\hline None $(<5 \mathrm{ppm})$ & 143 & 69.6 & {$[57.7-84.1]$} & \multirow{3}{*}{$<0.001$} \\
\hline Insufficient (5-14.9 ppm) & 75 & 96.3 & [73.8-124.7] & \\
\hline Adequate $(15+\mathrm{ppm})$ & 130 & 197.7 & [172.4-237.1] & \\
\hline
\end{tabular}

The $n$ 's are unweighted denominators in each subgroup; the sum of subgroups may not equal the total because of missing data. ${ }^{a}$ Medians are weighted for unequal selection probability.

${ }^{\mathrm{b}} \mathrm{CI}$ calculated by bootstrapping without taking into account the complex sampling design. Actual confidence intervals probably narrower. ${ }^{c} p$-Values are calculated using nonparametric median test. 
further investigate differences between nonpregnant nonlactating and lactating women, Supplementary Figure S1 presents an ecological analysis comparing UIC for the two groups by region.

\section{lodine status among pregnant women}

Nationally, the median UIC in pregnant women indicates inadequate iodine status in this subpopulation (Table 4). However, similar to nonpregnant women, the level of household salt iodization was strongly associated with median UIC. There were no significant associations between median UIC and residence, age, wealth quintile, educational level, or trimester of pregnancy; due to the small sample size for pregnant women, data were not disaggregated by region.

\section{Ecological associations between urinary iodine status and salt iodization}

We also conducted an ecological analysis that compares region-specific median UIC in nonpregnant nonlactating women with region-specific median salt iodine content and region-specific household coverage with adequately iodized salt (Fig. 3A, B). Median UIC tends to increase as the median salt iodine increases and also as the coverage with adequately iodized salt increases. The intercept of the regression lines crossing the $\mathrm{y}$-axis (i.e., $0 \mathrm{ppm}$ salt iodine content or $0 \%$ coverage) indicates that these women would have a UIC of $76-102 \mu \mathrm{g} / \mathrm{L}$ if household salt was not iodized at all.

\section{Associations between household salt iodization status and geometric mean UIC among nonpregnant nonlactating women}

Table 5 shows the geometric mean UIC of nonpregnant nonlactating women for various age, residence, and wealth subgroups, presented separately according to household salt iodine categories (noniodized, inadequately iodized, or adequately iodized). Household salt iodization status is strongly associated with the geometric mean UIC. Moreover, this finding is consistent among all subgroups. Regardless of age, residence, or wealth, salt iodine content is a very important determinant of iodine status in nonpregnant nonlactating women in Uzbekistan. No direct statements about a subgroup's iodine status can be made from this table, since geometric mean UIC may not reflect the median UIC, which is used to judge a population's iodine adequacy.

\section{Discussion}

While Uzbekistan had previously conducted multiple iodine surveys, the UNS was the first nationally representative survey to quantitatively measure both household-level salt iodine concentrations and women's urinary iodine excretion. As such, the findings of the UNS provide a representative baseline to which future iodine assessments can be compared.

The most recent previous assessment of household salt iodine was the MICS 2006 that used rapid test kits based on starch solutions (7). In that survey, just over half of the salt

Table 4. Median Urinary Iodine Concentration in Pregnant Women, Uzbekistan 2017

\begin{tabular}{|c|c|c|c|c|}
\hline Characteristic & $\mathrm{n}$ & Median UIC & {$[C I]^{\mathrm{b}}$} & $\mathrm{p}-$ Value $^{\mathrm{c}}$ \\
\hline Total & 227 & 117.3 & [101.8-139.9] & - \\
\hline \multicolumn{5}{|l|}{ Urban/rural } \\
\hline Urban & 54 & 123.6 & [89.1-152.8] & \multirow[t]{2}{*}{0.85} \\
\hline Rural & 173 & 117.3 & [98.6-144.1] & \\
\hline \multicolumn{5}{|l|}{ Age (in years) } \\
\hline $15-19$ & 14 & 106.9 & [24.8-212.9] & \multirow[t]{4}{*}{0.45} \\
\hline $20-29$ & 168 & 110.9 & [88.6-139.2] & \\
\hline $30-39$ & 43 & 126.5 & [92.4-177.1] & \\
\hline $40-49$ & 2 & 50.9 & [27.9-73.8] & \\
\hline \multicolumn{5}{|l|}{ Wealth quintile } \\
\hline Poorest & 39 & 89.2 & [52.8-133.3] & \multirow[t]{5}{*}{0.16} \\
\hline Second & 51 & 118.0 & {$[76.8-153.5]$} & \\
\hline Middle & 45 & 149.2 & [102.1-217.2] & \\
\hline Fourth & 47 & 101.4 & [69.6-165.9] & \\
\hline Wealthiest & 41 & 137.4 & [100.4-199.9] & \\
\hline \multicolumn{5}{|l|}{ Educational level } \\
\hline Secondary or less & 62 & 112.5 & [86.4-151] & \multirow[t]{2}{*}{0.69} \\
\hline Special secondary or more & 165 & 117.6 & [96.7-143.7] & \\
\hline \multicolumn{5}{|l|}{ Trimester of pregnancy } \\
\hline 1 & 58 & 109.7 & [74.3-164] & \multirow[t]{3}{*}{0.25} \\
\hline 2 & 91 & 136.8 & [94.5-191.9] & \\
\hline 3 & 72 & 106.5 & [86.0-134.0] & \\
\hline \multicolumn{5}{|c|}{ Level of iodization of household salt } \\
\hline None $(<5 \mathrm{ppm})$ & 96 & 78.4 & [54.3-97.7] & \multirow[t]{3}{*}{$<0.001$} \\
\hline Insufficient (5-14.9 ppm) & 36 & 106.9 & [51.4-161.2] & \\
\hline Adequate $(15+\mathrm{ppm})$ & 72 & 205.8 & [176.1-253.4] & \\
\hline
\end{tabular}

The $n$ 's are unweighted denominators in each subgroup; the sum of subgroups may not equal the total because of missing data. ${ }^{a}$ Medians are weighted for unequal selection probability.

${ }^{\mathrm{b}} \mathrm{CI}$ calculated by bootstrapping without taking into account the complex sampling design. Actual confidence intervals probably narrower. ${ }^{c} p$-Values are calculated using nonparametric median test. 

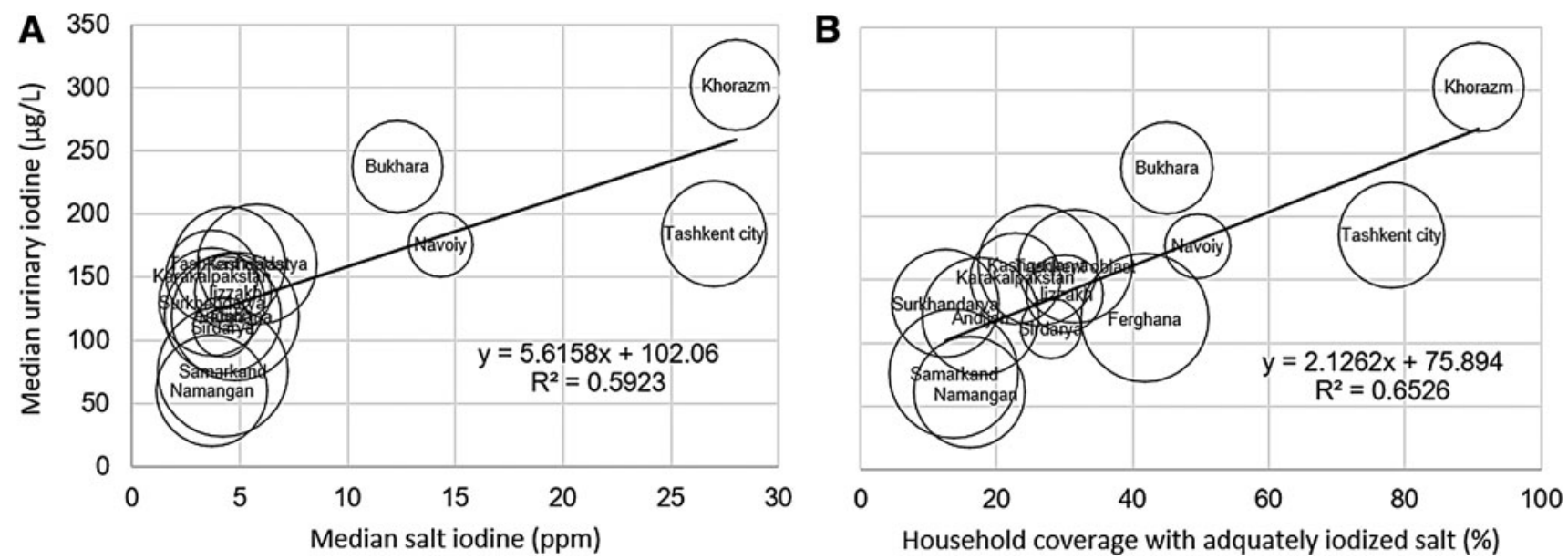

FIG. 3. Ecological comparison of median UIC among nonpregnant nonlactating women 15-49 years of age as a function of (A) median household salt iodine content and (B) household coverage with adequately iodized salt, Uzbekistan 2017; size of the circles is proportionate to the total population size in the respective region.

was found to be iodized, which is slightly lower but comparable with the results of the UNS. Although the MICS report claims "adequate" levels, rapid test kits have been demonstrated to be an unreliable semiquantitative or quantitative measurement of salt iodine content; as a result, it provides a poor measurement of household coverage with adequately iodized salt. Rapid test kits are especially poor at distinguishing between salt containing some but inadequate levels of iodine and salt containing adequate levels of iodine (6). Other more recent assessments in Uzbekistan using quantitative iodometric titration demonstrated higher household coverage with adequately iodized salt (e.g., 76\% for 2016), but these were school-based surveys where salt samples were brought from home by randomly selected students (8).

While the UNS found that more than $50 \%$ of household salt in Uzbekistan contains iodine, only about a third is adequately iodized. This coverage is far below the internationally recognized threshold of $90 \%$ coverage required to declare the elimination of iodine deficiency disease in a

Table 5. Weighted Geometric Mean Urinary Iodine in Nonpregnant Nonlactating Women 15-49 Years of Age, by Various Demographic Characteristics and Salt Iodine Categories, Uzbekistan 2017

\begin{tabular}{|c|c|c|c|c|c|c|c|}
\hline \multirow[b]{2}{*}{ Characteristic } & \multicolumn{2}{|c|}{$\begin{array}{l}\text { Women in households } \\
\text { with no salt iodine } \\
\quad(<5 \text { ppm })\end{array}$} & \multicolumn{2}{|c|}{$\begin{array}{c}\text { Women in households } \\
\text { with inadequate salt iodine } \\
(5-14.9 \text { ppm })\end{array}$} & \multicolumn{2}{|c|}{$\begin{array}{c}\text { Women in households } \\
\text { with adequate salt iodine } \\
(15+\text { ppm })\end{array}$} & \multirow[b]{2}{*}{$\mathrm{p}-$ Value $e^{\mathrm{b}}$} \\
\hline & $\mathrm{n}^{\mathrm{a}}$ & $\begin{array}{c}\text { Weighted geometric } \\
\text { mean UIC }(\mu g / L)\end{array}$ & $\mathrm{n}^{\mathrm{a}}$ & $\begin{array}{c}\text { Weighted geometric } \\
\text { mean UIC }(\mu \mathrm{g} / \mathrm{L})\end{array}$ & $\mathrm{n}^{\mathrm{a}}$ & $\begin{array}{l}\text { Weighted geometric } \\
\text { mean UIC }(\mu g / L)\end{array}$ & \\
\hline \multicolumn{8}{|l|}{ Age (in years) } \\
\hline $15-19$ & 110 & 91.5 & 40 & 150.1 & 98 & 225.7 & $<0.001$ \\
\hline $20-24$ & 98 & 97.4 & 42 & 121.0 & 77 & 218.3 & $<0.001$ \\
\hline $25-29$ & 76 & 85.5 & 46 & 151.1 & 85 & 191.8 & $<0.001$ \\
\hline $30-34$ & 109 & 95.6 & 45 & 135.5 & 85 & 183.4 & $<0.001$ \\
\hline $35-39$ & 86 & 82.1 & 27 & 120.0 & 74 & 151.2 & $<0.001$ \\
\hline $40-44$ & 84 & 84.2 & 42 & 145.8 & 74 & 178.2 & $<0.001$ \\
\hline $45-49$ & 105 & 83.4 & 54 & 121.6 & 86 & 198.9 & $<0.001$ \\
\hline \multicolumn{8}{|l|}{ Residence } \\
\hline Urban & 157 & 102.4 & 83 & 168.6 & 207 & 165.0 & $<0.001$ \\
\hline Rural & 512 & 85.0 & 214 & 124.0 & 373 & 210.5 & $<0.001$ \\
\hline \multicolumn{8}{|l|}{ Wealth index } \\
\hline Lowest & 184 & 77.9 & 63 & 103.8 & 56 & 133.9 & 0.008 \\
\hline Second & 134 & 82.4 & 63 & 121.8 & 101 & 215.2 & $<0.001$ \\
\hline Middle & 119 & 87.5 & 60 & 176.1 & 144 & 222.6 & $<0.001$ \\
\hline Fourth & 116 & 92.0 & 46 & 151.3 & 124 & 207.1 & $<0.001$ \\
\hline Highest & 109 & 114.4 & 64 & 137.4 & 154 & 169.8 & 0.004 \\
\hline
\end{tabular}

\footnotetext{
${ }^{a} n$ 's are unweighted numbers in each subgroup; the sum of subgroups may not equal the total because of missing data. Total sample size $=817$.

${ }^{\mathrm{b}} p$-Values derived from generalized linear model with $\ln [\mathrm{UIC}]$ as dependent variable. This analysis accounts for complex sampling. All $p$-values were 0.01 or below.
} 
country (11). The UNS confirms that salt is an appropriate food vehicle to increase the iodine status of the population by demonstrating a strong association between consumption of adequately iodized salt and UIC. To improve the coverage of adequately iodized salt, regulatory monitoring efforts should be enhanced to ensure that all salt in Uzbekistan complies with national mandatory standards. Although Uzbekistan imports limited amounts of its table salt $(21,22)$, regulatory monitoring should include salt imports.

Regulatory monitoring efforts can also ensure accurate labeling of table salt. The UNS found that salt iodine content is inversely associated with salt iodization claims on the packaging. Knowledge about salt iodization is good in the population of Uzbekistan, but poor package labeling makes it difficult for consumers to choose iodized salt.

Although other variables, such as residence, region, age, and household wealth quintile, were associated with women's iodine status, household salt iodine content has the strongest and most consistent association in both nonpregnant nonlactating and lactating women, and pregnant women. Similar strong associations between iodine status and the presence of iodized salt have been shown in other countries (23). The UNS provides several pieces of evidence that salt iodization improves women's iodine status. This strong association is evident in all subgroups examined, including in nonpregnant nonlactating, nonpregnant lactating, and pregnant women. Moreover, there is a substantial dose/response relationship between salt iodization and women's iodine status. These results cannot prove causality because they are based on data from a cross-sectional survey. Nonetheless, three important criteria for causal inference are present in our results: strength of association, consistency of the association in different groups, and dose/response (24).

\section{Conclusion}

Coverage with adequately iodized salt is low in Uzbekistan, and regardless of their physiological status (pregnant, lactating), age, residence and wealth, women in households with adequately iodized salt have substantially better iodine status than those living in households with inadequately or noniodized salt. This highlights the crucial importance and effectiveness of salt iodization and the need to strengthen this program in Uzbekistan.

\section{Acknowledgments}

The "Südwestdeutsche Salzwerke AG" (Heilbronn, Germany) and the laboratory of Human Nutrition Laboratory, Institute of Food, Nutrition and Health, ETH (Zurich, Switzerland) are acknowledged for their kind provision of external quality control samples. The U.S. Centers for Disease Control and Prevention (Atlanta, Georgia) conducted quality control trainings before laboratory analysis. DGP research and consulting company (Tashkent, Uzbekistan) conducted data collection.

\section{Author Disclosure Statement}

None of the authors declare a conflict of interest with regard to the content of this article. The findings and conclusions in this report are those of the authors and do not necessarily represent the official position of UNICEF.
UNICEF as the funding organization was involved in the design and collection of data, but was not involved in data analysis and reporting, nor in the decision to publish this article.

\section{Authors' Contributions}

F.R., F.N., N.P., J.P.W., and B.A.W. conceived the study and prepared for data collection; F.R., F.N., N.P., R.W., J.P.W., and B.A.W. managed data collection; F.R., N.P., B.A.W., and J.P.W. conducted data analysis; F.Y. and S.I. conducted laboratory analysis; F.R. and B.A.W. prepared the first draft of the article. All authors reviewed the first and subsequent drafts of the article and approved the final version for submission.

\section{Funding Information}

Funding for the survey and the publication of this article was received from UNICEF (agreement \#43266876).

\section{Supplementary Material}

\section{Supplementary Figure S1}

\section{References}

1. Pearce EN, Andersson M, Zimmermann MB 2013 Global iodine nutrition: where do we stand in 2013? Thyroid 23: 523-528.

2. Andersson M, Karumbunathan V, Zimmermann MB 2012 Global iodine status in 2011 and trends over the past decade. J Nutr 142:744-750.

3. Bath SC, Steer CD, Golding J, Emmett P, Rayman MP 2013 Effect of inadequate iodine status in UK pregnant women on cognitive outcomes in their children: results from the Avon Longitudinal Study of Parents and Children (ALSPAC). Lancet 382:331-337.

4. Bougma K, Aboud FE, Harding KB, Marquis GS 2013 Iodine and mental development of children 5 years old and under: a systematic review and meta-analysis. Nutrients 5: 1384-1416.

5. Zimmermann MB, Boelaert K 2015 Iodine deficiency and thyroid disorders. Lancet Diabetes Endocrinol 3:286-295.

6. Gorstein J, van der Haar F, Codling K, Houston R, Knowles J, Timmer A 2016 Performance of rapid test kits to assess household coverage of iodized salt. Public Health Nutr 19: 2712-2724.

7. UNICEF and State Statistical Committee of the Republic of Uzbekistan 2016 Uzbekistan Multiple Indicator Cluster Survey 2006. Tashkent, Uzbekistan.

8. Ismailov SI, Rashitov MM 2017 Results of epidemiological studies on the prevalence of iodine deficiency disorders in the Republic of Uzbekistan. Int J Endocrinol 13: 197-201.

9. Wong EM, Sullivan KM, Perrine CG, Rogers LM, PeñaRosas JP 2011 Comparison of median urinary iodine concentration as an indicator of iodine status among pregnant women, school-age children, and nonpregnant women. Food Nutr Bull 32:206-212.

10. Rohner F, Zimmermann M, Jooste P, Pandav C, Caldwell K, Raghavan R, Raiten DJ 2014 Biomarkers of nutrition for development-iodine review. J Nutr 144:1322S-1342S.

11. WHO/UNICEF/ICCIDD 2007 Assessment of iodine deficiency disorders and monitoring their elimination: a guide for programme managers. Third edition. WHO Library Cataloguing, Geneva, Switzerland. 
12. Pino S, Fang SL, Braverman LE 1996 Ammonium persulfate: a safe alternative oxidizing reagent for measuring urinary iodine. Clin Chem 42:239-243.

13. Jooste PL, Strydom E 2010 Methods for determination of iodine in urine and salt. Best Pract Res Clin Endocrinol Metab 24:77-88.

14. Zimmermann MB, Andersson M 2012 Assessment of iodine nutrition in populations: past, present, and future. Nutr Rev 70:553-570.

15. Filmer D, Pritchett LH 2001 Estimating wealth effects without expenditure data — or tears: an application to educational enrollments in states of India. Demography 38:115-132.

16. Vyas S, Kumaranayake L 2006 Constructing socioeconomic status indices: how to use principal components analysis. Health Policy Plan 21:459-468.

17. Bartier PM, Keller CP 1996 Multivariate interpolation to incorporate thematic surface data using inverse distance weighting (IDW). Comput Geosci 22:795-799.

18. GIS Geography. Raster resampling for discrete and continuous data. Available at https://gisgeography.com/rasterresampling (accessed June 19, 2019).

19. QGIS Development Team. QGIS Geographic Information System. Available at https://www.qgis.org/en/site/ (accessed June 19, 2019).

20. Center for International Earth Science Information Network-CIESIN-Columbia University 2018 Gridded Population of the World, Version 4 (GPWv4): Population Density Adjusted to Match 2015 Revision UN WPP Country Totals, Revision 11. Palisades, NY: NASA So- cioecon Data Appl Cent (SEDAC). Available at https://doi .org/10.7927/H4F47M65 (accessed November 21, 2019).

21. Observatory of Economic Complexity 2017 Salt Import Uzbekistan. Available at https://oec.world/en/visualize/tree_map/ hs92/import/uzb/show/2501/2017/ (accessed October 15, 2019).

22. Ismailov SI 2016 Economic analysis of the universal salt iodization program in Uzbekistan: cost-benefit analysis (Экономический анализ ШроГраммы всеобщеГо йодирования соли в Узбекстане: анализ издержек и выГ од). Tashkent, Uzbekistan.

23. Rohner F, Wirth JP, Woodruff BA, Chiwile F, Yankson H, Sesay F, Koroma AS, Petry N, Pyne-Bailey S, Dominguez E, Kupka R, Hodges MH, De Onis M 2016 Iodine status of women of reproductive age in Sierra Leone and its association with household coverage with adequately iodized salt. Nutrients 8:74.

24. Potischman N, Weed DL 1999 Causal criteria in nutritional epidemiology. Am J Clin Nutr 69:1309S-1314S.

Address correspondence to:

Fabian Rohner, PhD

GroundWork

Hintergasse 1

Fläsch 7306

Switzerland

E-mail: fabian@groundworkhealth.org 